\title{
Research on the Risk of Human Resource Management Outsourcing for First-class Hotel --- A Case of InterContinental Shenzhen
}

\author{
Wenli Li ${ }^{1, *}$, Ling Ren ${ }^{2}$ \\ ${ }^{1}$ Shenzhen Tourism College, Jinan University, China \\ ${ }^{2}$ Management College, Jinan University, China
}

Copyright $\odot 2016$ by authors, all rights reserved. Authors agree that this article remains permanently open access under the terms of the Creative Commons Attribution License 4.0 International License

\begin{abstract}
Hotel is a labor-intensive service industry, whose core competitiveness lies in the human resource. To establish cooperative relationship by entrusted agency model way is an inevitable choice which can reduce the workload and obtain more information and professional service. Nowadays, the internal and external environment is changing dramatically and the outsourcing market and related regulations are inadequate. The enterprises need to identify and control multiple risks during outsourcing process, and try to avoid threatening uncertainty for business development. In this study, firstly, literature review summarized the risks in the whole outsourcing process. Then the paper studied the case of InterContinental Shenzhen, analyzed current situation situations and problems of First-class Hotel's human resource management outsourcing, evaluated the risk factors by probability and impact comprehensively, rating the final data by risk matrix. Finally, this paper proposed the management strategies against the relatively serious risk factors. It aims to improve the consciousness of outsourcing risks by research and analysis, to provide valuable references for managers to identify the key risk and re-assign resources, to create sustainable competitive and to innovate and improve the mode of human resource management.
\end{abstract}

Keywords Human Resource Management, Outsourcing, Risk Management

\section{Introduction}

In the late 1970s, against the background of the fierce competition and the increasing market liquidity in the world, outsourcing of human resource management emerged and applied in the field of practice. Gradually, the human resource management is undertaken by the human resource department through the cooperation of enterprises with the organizations providing external human resource services, rather than sole undertaking by the individual department within the enterprises. Hotel, as one of the labor-intensive service industries, is faced with more soft-power competitions relating to technology and service in its operations. Thus, to a large extent, outsourcing of human resource management can help the hotel not only broaden the sources of income and economize on expenditures, but also optimize the allocation of resources \& personnel and increase the rate of operating income. However, in the outsourcing process, hotel is confronted with uncertainties from both the external and internal environment, along with external service organizations. Moreover, insufficient sharing of information in cooperation, together with the lack of professional guidance and supervision of policies as well as regulations in the rapid expansion of outsourcing market, has resulted in the increasingly prominent risks in practice.

Through field survey interviews and expert scoring method, this paper analyses the status of human resource management and the implementation of outsourcing of Shenzhen InterContinental Hotel, while it identifies and evaluates the risk factors comprehensively within the outsourcing activities of human resource management. Moreover, the paper introduces the risk assessment matrix to rate the risk factors according to their importance, after which it puts forward the risk control strategy on the basis of the results. Consequently, managers can reasonably allocate resources to control the uncertain factors related to outsourcing, thus maximizing its efficiency.

\section{Literature Review}

\subsection{Human Resource Management Outsourcing}

In 1990, American scholars Prahalad, C.K. and Hamel Gary firstly put forward the concept of "outsourcing" in The Core Competence of the Corporation on Harvard Business 
Review. Compared with producing products and services with enterprises' own employees, enterprises would get such products and services from external business contractors after signing contracts [1]. Lee Gretchen held the viewpoint that human resource management outsourcing would enable the enterprises to make greater profits with good cost performance, especially for the smaller companies with limited resources. With the help of outsourcing, they could acquire greater quality management and integrate their advantageous resources so as to promote their development [2]. Monca Belcourt gave a definition that human resource management outsourcing is a kind of innovation for the management mode, with which enterprises would utilize the external good resources. In this way, they would achieve lower operating costs, improve work efficiency, fully embodies their core competitiveness and enhance their adaptability to the changing environment. Generally, through outsourcing, the internal work is transferred to the external service provider [3].

\subsection{The Risk of Human Resource Management Outsourcing}

James A. Tompkins and Dale Marmelink analyzed the risk of human resource management outsourcing from four aspects: outsourcing strategy, outsourcing options, outsourcing implementation and outsourcing management, comprehensively covering forty types of possible risks in detail [4]. As for the entire outsourcing process, the following steps are included: conducting strategic decision-making, outsourcing human resource management activities or not; choosing outsourcing functions, outsourcing supplier and way of cooperation; and then in the process of outsourcing, undertaking the obligation of regulators to coordinate internal relations and follow up communication; finally, outsourcing quality feedback, assessment of cost and performance benefits.

\subsection{Human Resource Management Outsourcing for Hotel}

Hotel is a typical labor-intensive service industry, whose staff would directly affect the quality of services provided by the hotel. In other words, competitiveness is determined by the effect of human resource management. As a kind of creative management model, human resource management outsourcing for hotel could focus the limited resources on the core business, reduce the cost of daily management and then entrust the relatively cumbersome operational functions to the external organizations. As a result, professional advantages and rich resources of human resources service organization can be integrated, thus optimizing the structure and resource allocation of internal organization. However, due to the complexity of the business environment and enterprise's poor ability of self-cognition as well as external risk prediction, there is certain risk that outsourcing activities will be invalid or cannot achieve the desired goal [6].

\section{Method}

\subsection{Case Study Research}

Case study research is to investigate and analyze a specific object, for the purpose of further understanding its characteristics and the formation process. In this paper, Intercontinental Shenzhen is taken as an example. Based on field survey and in-depth interviews, it aims to deeply understand the current situation of human resource management outsourcing for the first-class hotel, as well as the existing problems and the main risk in the actual outsourcing work.

\subsection{Risk Assessment}

Through the combination of the analytic method of risk factor with the assessment method of internal control, the objectives, strategies and institutions in the management process are to be understood in principles of comprehensiveness, importance and objectivity; moreover, the risk evaluation matrix is introduced to do importance weight ranking.

\subsubsection{Risk Identification System}

Identify risk sources and determine the conditions as well as basis of their occurrence to take the risk control strategies. Through literature review and industry data report, this paper summarizes 17 risk factors involved in the process of human resource management outsourcing based on the four stages of human resource management outsourcing and three principal aspects of risk sources. After that, the selection through field survey and expert interview method has been conducted, along with specific outsourcing project and management status of the hotel, so as to exclude non-relevant or negligible factors, extract 10 major risk factors involved in the human resource management outsourcing for first-class hotel and build a risk identification system. 
Table 1. Risk Identification System of Hotel Human Resource Management Outsourcing Risk

\begin{tabular}{|c|c|c|}
\hline \multirow{11}{*}{$\begin{array}{l}\text { Human Resource Management } \\
\text { Outsourcing Risk for } \\
\text { InterContinental Shenzhen }\end{array}$} & Outsourcing Procedure & 10 major risk factors \\
\hline & \multirow{2}{*}{ Preparation phase } & A1 Decision making risk of outsourcing project \\
\hline & & A2 Potential high cost \\
\hline & \multirow{2}{*}{ Selection phase } & B1 The risk of converse selecting cause by information asymmetry \\
\hline & & B2 The risk of outsourcing contract \\
\hline & \multirow{4}{*}{ Implementation phase } & C1The risk of employee resistance \\
\hline & & C2 The risk of enterprises lacking monitoring capacity \\
\hline & & C3 The moral risk of outsourcer \\
\hline & & C4 The instability risk of outsourcer \\
\hline & \multirow{2}{*}{ Exit phase } & D1 The risk of enterprise's information security \\
\hline & & D2 Incompetence of analyzing cost and benefit \\
\hline
\end{tabular}

Table 2. Risk Assessment Criteria

\begin{tabular}{|c|c|c|c|c|c|}
\hline Level & 1 & 2 & 3 & 4 & 5 \\
\hline Probability & $0 \% \sim 10 \%$ & $11 \% \sim 40 \%$ & $41 \% \sim 60 \%$ & $61 \% \sim 90 \%$ & $91 \% \sim 100 \%$ \\
\hline Impact Level & 1 & 2 & 3 & 4 & 5 \\
\hline Degree & Negligible loss & Trivial loss & General loss & Severe loss & Intolerable loss \\
\hline Risk Level & A & B & C & D & E \\
\hline significance & Negligible Risk & Trivial Risk & Moderate Risk & Severe Risk & Key Risk \\
\hline
\end{tabular}

\subsubsection{Risk Assessment Criteria}

The severity of the risk is the comprehensive result of the probability of occurrence and the degree of impact (The severity of the risk $=$ the probability of occurrence $*$ the degree of impact). With the employment of the expert scoring method, this paper introduces Matrix Risk management tool to evaluate the 10 major risk factors involved in the outsourcing for hotel industry and grade risk ranks, thereby conducting the importance weight ranking. According to historical data and similar studies, 5 levels of risk probability and impact degree assessment criteria have been confirmed [7].

\subsection{Expert Scoring Method}

Expert scoring method, also known as the Delphi method, is an evaluation method which can be used to quantify the qualitative description. Firstly, according to the specific requirements and research purposes of assessment objects, the assessment factors and assessment criteria are determined while in an anonymous way, suggestions are inquired from many experts objectively. After that, the data are collected, and the initial feedback as well as the suggestions inquired for many times will be finally summarized for a uniform scientific result. When it comes to the reasonable evaluation, it serves as an effective method for some factors difficult to be assessed in a quantified way, which can thus analyze the severity of the risk and controllable degree.

\section{Case Study}

InterContinental Hotel Management Group has developed into the world's largest professional hotel management group the most extensive spreading range. It is dedicated to continuously and stably providing quality service and pursuing excellence so as to create the world's top hotel brand. Under the circumstance of continuous decline of the domestic hotel industry performance, the annual total revenue of InterContinental Shenzhen keeps in the leading place among over 200 hotels of Intercontinental Hotel group in China.

\subsection{Current Situation of Human Resource Management Outsourcing for InterContinental Shenzhen}

Through field survey, the human resource manager and the person in charge of the relevant functions are interviewed. Moreover, based on six major modules of human resource management, the human resource management policies and outsourcing situation of InterContinental Shenzhen have been understood in an overall way.

1) The construction of information platform: InterContinental Shenzhen purchases and uses SHIJI human resource management system, with its main function modules including: recruitment training, personnel information management, salary and welfare, social insurance, and providing overall and integrated solutions.

2) Recruitment Management: In order to meet a large number of employment needs, and in response to the 
volatility and high turnover rate problems, outsourcing modes in diversified recruitment channels include school-enterprise cooperation internship program, agreements with recruitment websites, and recruiting senior management or technical personnel through the collaboration with head-hunting companies.

3) Personnel leasing: The hotel will recruit outsourcing jobs characterized by high cost, relatively single channel and high turnover rate, such as the security and the cleaning, more than $85 \%$ of which are presented in the form of long-term personnel leasing. At the same time, short-term lease deals with the volatile employment needs, e.g. helpers are sent directly by service companies in case of a large banquet.

4) Specialized Training: In order to obtain more specialized services, and to make up for their resources and capacity, outsourcing modes are applied to the in-service training and professional skills certification training of the hotel executives, such as the International Platinum housekeeper certification, Golden Key concierge authorization and International trainer courses. Moreover, hotel groups could provide a good development platform for employees through the cooperation with professional league organization or training institution.

5) Satisfaction Survey: Employee satisfaction surveys and customer satisfaction surveys will be outsourced to TNS market research firm. For the external organizations, they are in charge of the regular implementation of research work and sending the final data analysis directly to the hotel, on which basis their own resources and investment could be saved, while a more objective and comprehensive finding can be obtained.

\subsection{Analysis on Evaluation Results}

Risk factors are classified according to the final data marked by 8 experts. (The experts are human resource manager, recruitment supervisor, trainer of front office, and F\&B manager from InterContinental shenzhen, 2 professional and well-experienced supervisor from HR service company, and 2 professors of management.) The leading five risk factors relating to the human resource management outsourcing process of high-star hotels are: B1 The risk of converse selecting cause by information asymmetry; A1 Decision-making risk of outsourcing project; B2 The risk of outsourcing contract; C2 The risk of enterprises lacking monitoring capacity; D1The risk of enterprise's information security, which belongs to $\mathrm{C}$ grade and D grade. In case of occurrence, the hotel will suffer serious damages, thus hindering the quality of key work and the achievement of core objectives. Therefore, there is a need to strengthen risk precautionary measures, if necessary, so as to change the outsourcing options or outsourcing modes, and make contingency plans for such risks.

As shown in the final data analysis from experts scoring, the most important risk is the information asymmetry which leads to the risk of outsourcing. In the process of the establishing the principal-agent relationship, it is very difficult to obtain the information of the hotel to make a comparison among and select for human resource managers due to the lack of enough information and the limitation in the indirect channels. Secondly, due to the characteristics of the industry and the difference of hotel's actual operating management in the implementation process of the outsourcing, human resources management is required to clarify their own goals and development direction in choosing the appropriate outsourcing project. Once there is false decision-making, it will lead to increased management costs, thus causing the reduction of the employee loyalty, risk of hotel business information, etc.

Table 3. Experts scoring data results

\begin{tabular}{|c|c|c|c|c|c|c|}
\hline \multirow{11}{*}{$\begin{array}{l}\text { Human resource } \\
\text { management } \\
\text { outsourcing of } \\
\text { OCT } \\
\text { Intercontinental } \\
\text { Hotel }\end{array}$} & Outsourcing process & Ten main risk factors & Probability & $\begin{array}{c}\text { Influence } \\
\text { degree }\end{array}$ & $\begin{array}{c}\text { Overall } \\
\text { score }\end{array}$ & $\begin{array}{l}\text { Risk } \\
\text { level }\end{array}$ \\
\hline & \multirow{2}{*}{ A Preparation phrase } & $\begin{array}{l}\text { A1 Decision making risk of outsourcing } \\
\text { project }\end{array}$ & 2.7 & 4.3 & 11.61 & $\mathrm{C}$ \\
\hline & & A2 potential high cost & 2.7 & 2.8 & 7.56 & B \\
\hline & \multirow{2}{*}{ B Selection phrase } & $\begin{array}{l}\text { B1 The risk of converse selecting cause by } \\
\text { information asymmetry }\end{array}$ & 3.5 & 4.2 & 14.70 & $\mathrm{D}$ \\
\hline & & B2 The risk of outsourcing contract & 3.2 & 3.3 & 10.56 & $\mathrm{D}$ \\
\hline & \multirow{4}{*}{$\begin{array}{l}\text { C Implementation } \\
\text { phrase }\end{array}$} & C1The risk of employee resistance & 3.0 & 2.2 & 6.60 & B \\
\hline & & $\begin{array}{l}\text { C2 The risk of enterprises lacking monitoring } \\
\text { capacity }\end{array}$ & 3.5 & 3.0 & 10.50 & $\mathrm{C}$ \\
\hline & & C3 The moral risk of outsourcer & 3.0 & 2.5 & 7.50 & B \\
\hline & & C4 The instability risk of outsourcer & 1.8 & 2.8 & 5.04 & B \\
\hline & \multirow{2}{*}{ D Exit phrase } & $\begin{array}{l}\text { D1The risk of enterprise's information } \\
\text { security }\end{array}$ & 2.5 & 3.5 & 8.75 & $\mathrm{C}$ \\
\hline & & $\begin{array}{l}\text { D2 Incompetence of analyzing cost and } \\
\text { benefit }\end{array}$ & 2.0 & 2.5 & 5.00 & B \\
\hline
\end{tabular}


The risk of enterprise information security has been impacted seriously, but the enterprise already acquires a certain degree of information protection consciousness. As a result, the probability is lower, which belongs to the medium risk. Besides, more discretion should be taken in case of selecting outsourcing projects or providing information to outsourcing service providers. Compared the risk of outsourcing contract with the risk of inadequate monitoring of the enterprise, the risk of contract risk is slightly lower, but the impact is relatively greater. Furthermore, the agreement is difficult to fully cover all the sudden and the division of responsibility, once legal disputes are involved in the dispute. In the implementation phase of the outsourcing, the hotel assumes regulatory roles, while excessive supervision and control may cause unsmooth cooperation and indirect impacting on the quality of service. Meanwhile, with too lax supervision, it is unable to conduct timely and accurate evaluation on the effect of outsourcing, thus resulting in the loss of learning and innovation.

The results of comprehensive risk assessment show that the main risk factors are derived from the preparation stage, the selection stage, the implementation stage and the exit stage. It can be explained in the way that the risk control of human resource management outsourcing requires the dynamic management of the whole process, especially in the outsourcing selection stage. Therefore, human resource managers need to strengthen the risk awareness of cautious decision-making to the greatest extent, thus avoiding such risks.

\section{The Strategy of Human Resource Outsourcing Risk}

\subsection{Select the Suitable Outsourcing Provider with High Quality and Low Cost}

The factors that need to be considered in the selection of the outsourcing providers can be summarized into three dimensions: cost, quality and cooperation dimension [8]. Moreover, investigation shall also be conducted on the business background, management status, credit experience, professional projects, service evaluation and development prospects of the outsourcing business. Secondly, the explicit cost and implicit cost, along with the consistency of the culture and strategic objectives shall be fully considered so as to avoid the cultural conflict in the outsourcing process.

\subsection{The Selection of Outsourcing Project According to the Outsourcing Object}

In the phase of preparation, the risk of selecting the project by mistake should be avoided. Firstly, we should have a clear understanding and analysis about the outsourcing motives and objectives. Besides, we shall figure out the main responsibility of the draft of the outsourcing project plan and find the method of cost benefit evaluation. The basic principle is to internalize strategic business with high value, and to ensure their own information security and internal control; and to externalize the operational responsibilities with low value and difficult business with short resource. Furthermore, the human resources business, to different extents, will be transferred to the outsourcing business, while responsibility shall be assumed for the supervision of the results and timely adjustment or withdrawal of outsourcing projects.

\subsection{Be Familiar with the Related Rules and Sign the Careful Contract}

The long-term contract can effectively reduce the cost of sharing, due to which the current hotel outsourcing contract with the medium and long-term cooperation is in the majority. Therefore, to adapt to the external environment and the changes in the demand for both sides, the contract should be based on careful and rigorous attitude, along with certain flexibility and update. For example, the contract terms should make clear the specific business and phase of the completion of the plan; in terms of service costs, the cost structure, calculation method and the cost budget, they shall also be made clearly in detail.

\subsection{To Engage in Outsourcing Service and Establish the Supervision and Risk Prevention Mechanism}

As a dynamic management activity that runs through the whole process, controlling outsourcing risk needs the human resources department to carry out the continuous supervision of the outsourcing service. Moreover, it needs to accurately evaluate the service quality, identify potential risks and control the intensity of supervision. Furthermore, timely communication and coordination of outsourcing companies are required to promote cooperation and win-win development. To strengthen communication and coordination, the human resources department should cooperate with each department to supervise the quality of outsourcing and understand the opinions and suggestions; at the same time, the support and solution shall be provided for the employees in the outsourcing process.

\subsection{To Strengthen the Secure Awareness of Information and Sign the Confidentiality Clause}

Information security risks exist in the whole process of outsourcing, especially in the exit stage. The confidentiality clause in the outsourcing agreement is a powerful measure to avoid information risk, which can limit the outsourcing behavior through high cost breach penalty clause. In this way, it can emphasize the confidentiality obligation of the subcontractor through the constraints of laws, prohibit the outsourcing business from leaking confidential information on the purpose of business, and protect the privacy of employees and customers. 


\subsection{To Strengthen the Communication and Coordination with the Employees and Outsourcing Service Personnel}

Strengthen communication to obtain the recognition and understanding from the employee and to avoid the occurrence of employee resistance. Relevant business training shall be implemented to help employees adapt to the organization structure of outsourcing as soon as possible. Besides, through coordinating the relationship between outsourcing and internal staff, the two sides are responsible for effective docking support work and timely identification of risk, so as to make adjustments for the promotion of the goal achieved.

\section{Conclusions \& Limitation}

Human resource management outsourcing has achieved good development in China, and its service practice has been accepted by all lines of human resource managers. However, due to the limitation of the outsourcing from practice, the market operation and the relevant legal mechanisms are not perfect, while the external environment, service providers and enterprises are faced with uncertainties. Therefore, there are many risks causing threats to management objectives in the process of outsourcing.

It is shown from the result of risk factors sorted by importance that, the risk control in the process of human resource management outsourcing is a whole process of dynamic management, and it is also endowed with certain industrial characteristics. Due to different natures of the enterprise or different ways of outsourcing, there can be different degrees of the risk factors. Compared with the results of the risk assessment, the results of this study are in line with the characteristics of the hotel industry and the actual outsourcing. It is of positive significance and reference value for the same type of hotel, so as to optimize human resource management model and improve the efficiency of human resource management outsourcing.

In this paper, with the InterContinental Shenzhen Hotel as the main research object, the research results are representative to some degree. It can provide reference for the development of the same type of hotel outsourcing activities. However, there are still many problems which can be improved and enhanced in the future exploration, such as expanding the research objects and providing a more comprehensive as well as effective guidance for the human resources outsourcing risk management in the hotel industry. Furthermore, it aims to not only innovate the human resources outsourcing strategy and break the single choice, but also try to integrate multi resources through the internal and external reasonable arrangement, and reduce the overall risk through coordination and balance.

\section{REFERENCES}

[1] Prahalad, C. K. \& Hamel Gray. The core competence of the corporation, Harvard Business Review. 1990, 68(3): 79-91

[2] Lee, Gretchen. When should you outsource HR? [J]. Water Well Journal. 2004, 58(5)

[3] Monca Belcourt. Outsourcing - the benefits and the risks. Human Resource Management Review. 2006(16):269-279

[4] James A. Tompkins, Ph.D \& Dale Marmelink. 40 outsourcing risks you need to know now [J]. Logistics Today. 2004, 45(10)

[5] Liao Xiaoming, Zheng Nan. Risk and avoidance measures of enterprise human resource outsourcing. [J]. Soft Science. 2005(2)

[6] Sun Zehou, Huang Wenfu. Human resource management outsourcing risk management [J].Human Resource Development of China. 2003(12)

[7] Cai Ping. Research of enterprise human resource management outsourcing risk and control in China [D]. Chongqing Technology and Business University.2012(5)

[8] Liu Bing, Guo Caiyun. Outsourcing theory and method of enterprise human resources management [J]. Beijing: China Economic Press. 2006 